\title{
Young $T$ cells age during a redirected anti-tumor attack: chimeric antigen receptor-provided dual costimulation is half the battle
}

\author{
Andreas A. Hombach ${ }^{1,2}$ and Hinrich Abken ${ }^{1,2}$ * \\ ${ }^{1}$ Center for Molecular Medicine Cologne, University of Cologne, Cologne, Germany \\ ${ }^{2}$ Department I Internal Medicine, University Hospital Cologne, Cologne, Germany
}

Edited by:

Bruno Laugel, Cardiff University

School of Medicine, UK

\section{Reviewed by:}

PerThor Straten, University Hospital

Herlev Denmark, Denmark

Christoph Renner, University Hospital

Basel, Switzerland

${ }^{*}$ Correspondence:

Hinrich Abken, Center for Molecular

Medicine Cologne, University

Hospital Cologne, Robert-Koch-Str.

21, D-50931 Köln, Germany

e-mail: hinrich.abken@uk-koeln.de
Adoptive therapy with chimeric antigen receptor (CAR)-redirected T cells showed spectacular efficacy in the treatment of leukemia in recent early phase trials. Patient's T cells were ex vivo genetically engineered with a CAR, amplified and re-administered to the patient. While $T$ cells mediating the primary response were predominantly of young effector and central memory phenotype, repetitive antigen engagement irreversible triggers $T$ cell maturation leaving late memory cells with the $\mathrm{KLRG} 1^{+} \mathrm{CD} 57^{+} \mathrm{CD} 7^{-} \mathrm{CCR} 7^{-}$phenotype in the long-term. These cells preferentially accumulate in the periphery, are hypo-responsive upon TCR engagement and prone to activation-induced cell death. A recent report indicates that those T cells can be rescued by CAR provided CD28 and OX40 (CD134) stimulation. We discuss the strategy with respect to prolong the anti-tumor response and to improve the over-all efficacy of adoptive cell therapy.

Keywords: adoptive cell therapy, chimeric antigen receptor, memory T cells, CD28, OX40

\section{ADOPTIVE THERAPY WITH CAR ENGINEERED T CELLS} SHOWED SPECTACULAR EFFICACY IN EARLY PHASE TRIALS

Recent success in the immune therapy of malignant diseases has sustained the promise that the immune system can control cancer in the long-term. On the other hand, tumor-specific $\mathrm{T}$ cells are rare in cancer patients making their isolation and ex vivo amplification to therapeutic numbers necessary. To overcome the situation strategies were developed to engraft T cells with defined specificity by genetic engineering; the so-called "T-body" strategy equips patient's T cells with a recombinant trans-membrane receptor molecule which is composed in the extracellular part of an antibody-type recognition domain for MHC-independent binding and in the intracellular part of T cell activating domains, mostly the TCR CD3 $\zeta$ endodomain linked to a costimulatory domain like CD28, OX40, or 4-1BB (Gross and Eshhar, 1992; Eshhar, 2008). Such a chimeric antigen receptor (CAR) redirects $\mathrm{T}$ cells in an antigen-specific fashion producing specific $\mathrm{T}$ cell activation toward defined targets.

Second generation CAR's providing CD28 costimulation along with the primary $\mathrm{CD} 3 \zeta$ signal more effectively activate $\mathrm{T}$ cells than CAR's with $\mathrm{CD} 3 \zeta$ signaling only. This is basically due to the CD28 mediated improvement of $\mathrm{T}$ cell effector functions and the protection from activation-induced cell death resulting in prolonged persistence in vivo (Savoldo et al., 2011). Other costimulatory domains of the CD28 family, like 4-1BB (CD137), also improves T cell persistence (Milone et al., 2009; Song et al., 2011). Each individual costimulatory signal, however, differentially orchestrates the effector functions including cytokine secretion, amplification, and cytolytic activity (Hombach and Abken, 2011) which allows to modulate the anti-tumor response in a fine-tuned fashion.
Current clinical trials are utilizing second generation CARs to ensure prolonged persistence of engineered $\mathrm{T}$ cells in vivo. $\mathrm{T}$ cells engineered with a $4-1 \mathrm{BB}-\zeta$ CAR targeting CD19 recently produced spectacular efficacy toward refractory leukemia in patients with high tumor burden (Kalos et al., 2011; Grupp et al., 2013). Further studies in other centers are also reporting encouraging clinical responses using CD28- $\zeta$ CAR T cells (Brentjens et al., 2011; Kochenderfer et al., 2012). The general success of these studies is likely due to repetitive tumor cell killing by CAR T cells; additionally, the targeted CD19 is also expressed by healthy B cells which re-stimulate the CAR T cells independently of the targeted tumor cells. The situation in targeting solid tumors, however, is more complex, in particular with respect to immune repression, and may require supporting strategies as discussed in a recent review (Gilham et al., 2012). We here address an additional aspect which is attracting increasing attention and which is of equal relevance for the success in adoptive cell therapy: the progression of CAR redirected $\mathrm{T}$ cells into terminal maturation upon repetitive antigen encounter.

\section{REPETITIVE CAR ENGAGEMENT PRODUCES LATE EFFECTOR MEMORY CELLS WITH ALTERED FUNCTIONAL CAPACITIES}

Chimeric antigen receptor engineered young $\mathrm{T}$ cells, the majority of them with central memory phenotype, are adoptively transferred to the patient since these cells showed superior in mediating an anti-tumor response in pre-clinical models (Klebanoff et al., 2005). Repetitive binding to cognate antigen, however, induces CAR $\mathrm{T}$ cells to amplify, as $\mathrm{T}$ cells physiologically do upon TCR/CD28 engagement or TCR stimulation in presence of IL-2. Extensive amplification, however, substantially impacts the anti-tumor efficacy of CAR T cells in the long-term. After 
$<2$ weeks of cell divisions in vitro, $\mathrm{T}$ cells progress in maturation and alter their functional properties, associated by a change in phenotype (Figure 1). Repetitive antigen engagement converts naïve and central memory T cells to cells with a CCR7 ${ }^{-}$CD62 $\mathrm{L}^{\text {low }}$ $\mathrm{CD}_{57}{ }^{+} \mathrm{KLRG}^{+}$effector memory phenotype with $\mathrm{CD} 45 \mathrm{RO}^{\text {high }}$ CD45RA ${ }^{\text {low }}$ and CD27 $7^{\text {low }}$ CD28 $8^{\text {low }}$ expression. CAR mediated maturation occurs in both $\mathrm{CD}^{+}$and $\mathrm{CD} 4^{+} \mathrm{T}$ cells and does not happen when cell division is blocked. The process is observed in a mouse tumor model in which after adoptive transfer of young $\mathrm{CCR}^{+}{ }^{+}$CAR T cells the majority of tumor infiltrating CAR T cells are of CCR7 ${ }^{\text {low }}$ phenotype (Hombach et al., 2013). One consequence is that the capacity of those cells to re-enter the lymph and to re-circulate is diminished since CCR7 is required for $\mathrm{T}$ cell homing into secondary lymphoid organs (Sallusto et al., 1999; Müller and Lipp, 2003; Bromley et al., 2005; Klebanoff et al., 2005; Moschovakis and Förster, 2012). Inability of CCR7 ${ }^{-}$T cells to re-circulate, on the other hand, may be of advantage since most solid cancer lesions occur in the periphery. The assumption is sustained by the observation that $\mathrm{CCR}^{-}{ }^{-} \mathrm{CAR} \mathrm{T}$ cells persist in higher numbers in the tumor lesion although both the CCR7 ${ }^{+}$ and CCR7 ${ }^{-}$subset $\mathrm{T}$ cells equally efficiently target to the tumor (Hombach et al., 2013). Paradoxically, the anti-tumor response of CCR7 $^{-}$CAR T cells is less efficient than that of CCR7 ${ }^{+} \mathrm{T}$ cells when redirected by a CD28- $\zeta$ CAR. This is moreover unexpected since CCR7 ${ }^{-}$T cells secrete higher amounts of pro-inflammatory cytokines like IFN- $\gamma$ and harbor higher levels of cytolytic effector molecules like perforin and granzymes compared to CCR7 ${ }^{+}$ $\mathrm{T}$ cells. Detailed analyses revealed that $\mathrm{CCR}^{-} \mathrm{T}$ cells are prone to spontaneous and activation-induced cell death which is insufficiently prevented by CAR mediated CD28 costimulation (Hombach et al., 2013). Similar observations were reported for CD57 ${ }^{+}$ T cells (Chattopadhyay et al., 2009) and which is in contrast to $\mathrm{CCR}^{+} \mathrm{T}$ cells.

Simultaneous CD28 and OX40 costimulation reduces the high propensity of CCR7 ${ }^{-} \mathrm{T}$ cells to undergo apoptosis (Hombach et al., 2013). OX40 promotes Bcl-xL and Bcl-2 expression, enhances the survival of antigen-experienced effector $\mathrm{T}$ cells and improves the generation of antigen-specific T cell memory (Rogers

\begin{tabular}{|c|c|c|c|c|c|c|c|c|c|c|c|}
\hline & \multicolumn{2}{|c|}{$\underline{\text { Naive T cells }}$} & \multicolumn{3}{|c|}{$\underline{T}$ (stem cell) Memory } & \multicolumn{2}{|c|}{ Central Memory } & \multicolumn{2}{|c|}{ Effector Memory } & \multicolumn{2}{|l|}{ TEMRA } \\
\hline $\begin{array}{c}\text { T cell } \\
\text { differentiation }\end{array}$ & $\begin{array}{l}\text { CD45RA } \\
\text { CD45R0 } \\
\text { CD62L } \\
\text { CCR7 } \\
\text { CD56 } \\
\text { CD57 } \\
\text { CD7 } \\
\text { CD28 } \\
\text { Per/Gran } \\
\text { KLRG1 }\end{array}$ & $\begin{array}{l}+++ \\
- \\
+++ \\
+++ \\
- \\
- \\
+++ \\
+++ \\
+ \\
-\end{array}$ & $\begin{array}{l}\text { CD45RA } \\
\text { CD45RO } \\
\text { CD62L } \\
\text { CCR7 } \\
\text { CD56 } \\
\text { CD57 } \\
\text { CD7 } \\
\text { CD28 } \\
\text { Per/Gran } \\
\text { KLRG1 }\end{array}$ & $\begin{array}{l}++ \\
- \\
++ \\
++ \\
- \\
- \\
++ \\
++ \\
+ \\
-\end{array}$ & & $\begin{array}{l}\text { CD45RA } \\
\text { CD45RO } \\
\text { CD62L } \\
\text { CCR7 } \\
\text { CD57 } \\
\text { CD56 } \\
\text { CD7 } \\
\text { CD28 } \\
\text { Per/Gran } \\
\text { KLRG1 }\end{array}$ & $\begin{array}{l}- \\
+++ \\
+ \\
++ \\
+ \\
- \\
++ \\
+++ \\
++ \\
+\end{array}$ & $\begin{array}{l}\text { CD45RA } \\
\text { CD45RO } \\
\text { CD62L } \\
\text { CCR7 } \\
\text { CD57 } \\
\text { CD56 } \\
\text { CD7 } \\
\text { CD28 } \\
\text { Per/Gran } \\
\text { KLRG1 }\end{array}$ & $\begin{array}{l}- \\
+++ \\
- \\
- \\
++ \\
+ \\
+ \\
+ \\
+++ \\
++\end{array}$ & $\begin{array}{l}\text { CD45RA } \\
\text { CD45RO } \\
\text { CD62L } \\
\text { CCR7 } \\
\text { CD57 } \\
\text { CD56 } \\
\text { CD7 } \\
\text { CD28 } \\
\text { Per/Gran } \\
\text { KLRG1 }\end{array}$ & $\begin{array}{l}++ \\
- \\
- \\
- \\
+++ \\
++ \\
- \\
(+) \\
+++ \\
+++\end{array}$ \\
\hline \multicolumn{12}{|l|}{ anergy } \\
\hline \multicolumn{12}{|l|}{ AICD } \\
\hline \multicolumn{12}{|l|}{ peripheral homing } \\
\hline \multicolumn{12}{|l|}{ central homing } \\
\hline \multicolumn{12}{|l|}{ T cell expansion } \\
\hline \multicolumn{12}{|l|}{ cytotoxicity } \\
\hline $\begin{array}{l}\text { costimulation required } \\
\text { to prevent apoptosis }\end{array}$ & \multicolumn{2}{|c|}{ CD28 } & \multicolumn{3}{|c|}{ CD28 } & \multicolumn{2}{|c|}{ CD28 } & \multicolumn{2}{|c|}{ CD28-OX40 } & \multicolumn{2}{|c|}{ CD28-OX40? } \\
\hline \multicolumn{5}{|c|}{$\begin{array}{l}\text { FIGURE } 1 \text { |T cell maturation is accompanied by altered functional } \\
\text { properties. CAR engineered T cells progress in maturation when the CAR } \\
\text { repetitively engages cognate antigen as physiologically occurs upon } \\
\text { TCR/CD28 signaling. While CAR engineered "young" memory T cells are } \\
\text { transferred to the patient, the cells expand and undergo further differentiation } \\
\text { leaving effector memory T cells at the tumor lesion which require additional }\end{array}$} & \multicolumn{7}{|c|}{$\begin{array}{l}\text { signals for being protected from anergy and activation-induced cell death. On } \\
\text { the other hand, those more matured cells have increased cytolytic potential } \\
\text { making them highly effective in the anti-tumor attack. Engineering T cells with } \\
\text { a combined CD28-OX40 CAR which prevents apoptosis of matured CCR7- } \\
\text { cells is one of the upcoming strategies to solve the situation and to improve } \\
\text { the anti-tumor efficacy in the long-term. }\end{array}$} \\
\hline
\end{tabular}


et al., 2001). In combination with CD28 in a so-called "third generation" CD28-OX40 CAR, combined costimulation improved survival and cytolytic activities of CCR7 ${ }^{-} \mathrm{T}$ cells toward targeted cancer cells (Hombach et al., 2013). Similar results were obtained with CD62 $\mathrm{L}^{-} \mathrm{T}$ cells which mature from CCR7 ${ }^{-} \mathrm{CD}^{-} \mathrm{L}^{+} \mathrm{T}$ cells upon stimulation (Hombach and Abken, 2011). The combination of costimulatory signals achieves the effect since OX40 alone does not provide benefit in this context whereas CD28 costimulation alone, which prevents $\mathrm{CCR} 7^{+} \mathrm{T}$ cell apoptosis, does not reduce the number of apoptotic CCR7 ${ }^{-}$cells. Taken together adoptive cell therapy will benefit from redirecting T cells by a CD28-OX40 CAR to provide protection from apoptosis when young cells progress in maturation.

\section{PERSPECTIVES: HOW TO MAINTAIN AN ANTI-TUMOR RESPONSE IN THE LONG-TERM?}

Several factors together are required to rescue matured CAR T cells for the anti-tumor response in the long-term.

First, any T cell subset converts to effector memory cells upon repetitive antigen engagement and amplification and in each stage of maturation requires appropriate costimulation to escape cell death; consequently, harnessing young T cells with a CD28-OX40 CAR will be beneficial and will rescue $\mathrm{CCR}^{-}$cells when produced during an anti-tumor attack.

Second, CCR7 ${ }^{-}$T cells persist in peripheral lesions due to their inability to re-enter the lymph, thereby increasing the probability for successful cancer cell killing. To improve their accumulation at the tumor site T cells were additionally engineered with the CCR2 receptor (Moon et al., 2011). Alternatively, CAR engineered T cells are injected into the tumor lesion taking advantage of the plethora of different effector $\mathrm{T}$ cell subsets in fighting cancer while circumventing the limitations in $\mathrm{T}$ cell trafficking. In contrast, i.v. injected $\mathrm{T}$ cells become stuck in the lungs for hours and subsequently accumulate in liver, spleen, and lymph nodes, while regional application produces $\mathrm{T}$ cell persistence at the injected tumor site with only local diffusion within the following days (Parente-Pereira et al., 2011). The strategy, however, requires good accessibility by direct puncture or by endoscopy and is currently evaluated in the treatment of head and neck cancer (EudraCT 2012-001654-25, NCT01722149) or will be applied to the treatment of cutaneous lymphoma (EudraCT 2011-003125-10).

Third, effector memory $\mathrm{T}$ cells produce increased levels of pro-inflammatory cytokines and cytolytic molecules, both contributing to improve cancer cell killing. Late memory $\mathrm{T}$ cells,

\section{REFERENCES}

Brentjens, R. J., Rivière, I., Park, J. H., Davila, M. L., Wang, X., Stefanski, J., et al. (2011). Safety and persistence of adoptively transferred autologous CD19-targeted $\mathrm{T}$ cells in patients with relapsed or chemotherapy refractory B-cell leukemias. Blood 118, 4817-4828. doi:10.1182/blood2011-04-348540

Bromley, S. K., Thomas, S. Y., and Luster, A. D. (2005). Chemokine receptor CCR7 guides $\mathrm{T}$ cell exit from peripheral tissues and entry into afferent lymphatics. Nat. Immunol. 6, 895-901. doi:10.1038/ni1240

Chattopadhyay, P. K., Betts, M. R., Price, D. A., Gostick, E., Horton, H., Roederer, M., et al. (2009). The cytolytic enzymes granyzme A, granzyme $\mathrm{B}$, and perforin: expression patterns, cell distribution, and their relationship to cell maturity and bright CD57 expression. J. Leukoc. Biol. 85, 88-97. doi:10.1189/jlb. 0208107

Eshhar, Z. (2008). The T-body approach: redirecting $\mathrm{T}$ cells

however, are TCR hypo-responsive which is due to an inefficient formation of the TCR synapse as a result of galectin-3 anchoring of TCR components. Interestingly, formation of a transgenic CAR synapse in those cells is not affected making them fully responsive to CAR targets (Rappl et al., 2012).

Since $\mathrm{T}$ cell expansion is mandatory to establish adoptively transferred $\mathrm{T}$ cells in the long-term, sufficient space is provided to transferred $\mathrm{T}$ cells by non-myeloablative lympho-depleting preconditioning followed by IL-2 administration to sustain expansion; other cytokines like IL-7 and IL-15 are also explored (Weber et al., 2011). Extensive T cell amplification, on the other hand, produces effector memory $\mathrm{T}$ cells which then need to be protected from activation-induced cell death. Other costimulation than by CD28 and OX40 may also provide benefit to those cells, for instance 4-1BB (Song et al., 2011). Co-signaling by 4-1BB and CD28 may also provide an advantage to matured T cells, however, needs to be evaluated in detail. The effect of each combination of costimulatory signals, however, cannot be predicted since the CAR with its linked endodomains provides simultaneous signaling while in the physiological situation the signals occur individually in a well-defined temporal and spatial order. An elegant solution of the dilemma is the use of virus-specific $\mathrm{T}$ cells which are further matured by the immune system and have some significant properties needed for effective anti-cancer therapy. These cells obtain survival and costimulatory signals when engaging virus-infected cells by their TCR. Current trials use EBV or CMV specific, autologous T cells engineered with a first or second generation CAR, for instance directed against ErbB2 (NCT01109095), CD30 (NCT01192464), CD19 (NCT00709033; NCT01475058; NCT01430390; NCT00840853; NCT01195480), or GD-2 (NCT00085930). Virus-specific T cells are long-lived in pre-clinical models in vivo, have a great capacity to amplify and are particularly applied in the context of allogeneic stem cell transplantation where they protect from virus re-activation and tumor relapse while having low risk of inducing graft versus host disease.

\section{ACKNOWLEDGMENTS}

Work in the author's laboratory is supported by the Deutsche Krebshilfe, the Wilhelm Sander-Stiftung, the European Union (European Regional Development Fund - Investing in your future) and the German federal state North Rhine-Westphalia (NRW), and the Fortune program of the Medical Faculty of the University of Cologne.

with antibody specificity. Handb. Exp. Pharmacol. 181, 329-342. doi:10.1007/978-3-540-73259-4_14

Gilham, D. E., Debets, R., Pule, M., Hawkins, R. E., and Abken, H. (2012). CAR-T cells and solid tumors: tuning $\mathrm{T}$ cells to challenge an inveterate foe. Trends Mol. Med. 18, 377-384. doi:10.1016/j.molmed. 2012.04.009

Gross, G., and Eshhar, Z. (1992). Endowing $\mathrm{T}$ cells with antibody specificity using chimeric $\mathrm{T}$ cell receptors. FASEB J. 6, 3370-3378.
Grupp, S. A., Kalos, M., Barrett, D. Aplenc, R., Porter, D. L., Rheingold, S. R., et al. (2013). Chimeric antigen receptor-modified $\mathrm{T}$ cells for acute lymphoid leukemia. $N$. Engl. J. Med. 368, 1509-1518. doi:10.1056/NEJMoa1215134

Hombach, A. A., and Abken, H. (2011). Costimulation by chimeric antigen receptors revisited the $\mathrm{T}$ cell antitumor response benefits from combined CD28-OX40 signalling. Int. J. Cancer 129, 2935-2944. doi:10.1002/ijc.25960 
Hombach, A. A., Chmielewski, M., Rappl, G., and Abken, H. (2013). Adoptive immunotherapy with redirected $\mathrm{T}$ cells produces CCR7(-) cells that are trapped in the periphery and benefit from combined CD28-OX40 costimulation. Hum. Gene Ther. 24, 259-269. doi:10. 1089/hum.2012.247

Kalos, M., Levine, B. L., Porter, D. L., Katz, S., Grupp, S. A., Bagg, A., et al. (2011). T cells with chimeric antigen receptors have potent antitumor effects and can establish memory in patients with advanced leukemia. Sci. Transl. Med.3, 95ra73. doi:10.1126/scitranslmed.300 2842

Klebanoff, C. A., Gattinoni, L., TorabiParizi, P., Kerstann, K., Cardones, A. R., Finkelstein, S. E., et al. (2005). Central memory self/tumor-reactive CD8+ T cells confer superior antitumor immunity compared with effector memory T cells. Proc. Natl. Acad. Sci. U.S.A. 102, 9571-9576. doi:10.1073/pnas.0503726102

Kochenderfer, J. N., Dudley, M. E., Feldman, S. A., Wilson, W. H., Spaner, D. E., Maric, I., et al. (2012). B-cell depletion and remissions of malignancy along with cytokine-associated toxicity in a clinical trial of anti-CD19 chimericantigen-receptor-transduced $\mathrm{T}$ cells. Blood 119, 2709-2720. doi:10.1182/blood-2011-10-384388

Milone, M. C., Fish, J. D., Carpenito, C., Carroll, R. G., Binder, G. K.,
Teachey, D., et al. (2009). Chimeric receptors containing CD137 signal transduction domains mediate enhanced survival of $\mathrm{T}$ cells and increased antileukemic efficacy in vivo. Mol. Ther. 17, 1453-1464. doi:10.1038/mt.2009.83

Moon, E. K., Carpenito, C., Sun, J., Wang, L.-C. S., Kapoor, V., Predina, J., et al. (2011). Expression of a functional CCR2 receptor enhances tumor localization and tumor eradication by retargeted human $t$ cells expressing a mesothelin-specific chimeric antibody receptor. Clin. Cancer Res. 17, 4719-4730. doi:10.1158/10780432.CCR-11-0351

Moschovakis, G. L., and Förster, R. (2012). Multifaceted activities of CCR7 regulate T-cell homeostasis in health and disease. Eur. J. Immunol. 42, 1949-1955. doi:10.1002/eji.201242614

Müller, G., and Lipp, M. (2003). Shaping up adaptive immunity: the impact of CCR7 and CXCR5 on lymphocyte trafficking. Microcirculation 10, 325-334. doi:10.1080/mic.10.34.325.334

Parente-Pereira, A. C., Burnet, J., Ellison, D., Foster, J., Davies, D. M., van der Stegen, S., et al. (2011). Trafficking of CAR-engineered human $\mathrm{T}$ cells following regional or systemic adoptive transfer in SCID beige mice. J. Clin. Immunol. 31, 710-718. doi:10.1007/s10875-0119532-8
Rappl, G., Riet, T., Awerkiew, S., Schmidt, A., Hombach, A. A., Pfister H., et al. (2012). The CD3-zeta chimeric antigen receptor overcomes TCR Hypo-responsiveness of human terminal late-stage $\mathrm{T}$ cells. PLoS ONE 7:e30713. doi:10.1371/journal.pone.0030713

Rogers, P. R., Song, J., Gramaglia, I., Killeen, N., and Croft, M. (2001). OX40 promotes Bcl-xL and $\mathrm{Bcl}-2$ expression and is essential for long-term survival of CD4 $\mathrm{T}$ cells. Immunity 15, 445-455. doi:10. 1016/S1074-7613(01)00191-1

Sallusto, F., Lenig, D., Förster, R., Lipp, M., and Lanzavecchia, A. (1999). Two subsets of memory $\mathrm{T}$ lymphocytes with distinct homing potentials and effector functions. Nature 401, 708-712. doi:10.1038/44385

Savoldo, B., Ramos, C. A., Liu, E. Mims, M. P., Keating, M. J., Carrum, G., et al. (2011). CD28 costimulation improves expansion and persistence of chimeric antigen receptor-modified $\mathrm{T}$ cells in lymphoma patients. J. Clin. Invest. 121, 1822-1826. doi:10.1172/JCI4 6110

Song, D.-G., Ye, Q., Carpenito, C. Poussin, M., Wang, L.-P., Ji, C., et al. (2011). In vivo persistence, tumor localization, and antitumor activity of CAR-engineered $\mathrm{T}$ cells is enhanced by costimulatory signaling through CD137 (4-1BB). Cancer Res. 71, 4617-4627. doi:10.1158/00085472.CAN-11-0422
Weber, J., Atkins, M., Hwu, P., Radvanyi, L., Sznol, M., and Yee, C. (2011). White paper on adoptive cell therapy for cancer with tumorinfiltrating lymphocytes: a report of the CTEP subcommittee on adoptive cell therapy. Clin. Cancer Res. 17, 1664-1673. doi:10.1158/10780432.CCR-10-2272

Conflict of Interest Statement: The authors declare that the research was conducted in the absence of any commercial or financial relationships that could be construed as a potential conflict of interest.

Received: 27 April 2013; paper pending published: 08 May 2013; accepted: 22 May 2013; published online: 05 June 2013.

Citation: Hombach $A A$ and Abken $H$ (2013) Young $T$ cells age during a redirected anti-tumor attack: chimeric antigen receptor-provided dual costimulation is half the battle. Front. Immunol. 4:135. doi: 10.3389/fimmu.2013.00135

This article was submitted to Frontiers in $T$ Cell Biology, a specialty of Frontiers in Immunology.

Copyright (c) 2013 Hombach and Abken. This is an open-access article distributed under the terms of the Creative Commons Attribution License, which permits use, distribution and reproduction in other forums, provided the original authors and source are credited and subject to any copyright notices concerning any third-party graphics etc. 